\title{
Reflexões sobre as interfaces entre a modelagem paramétrica e outros processos de representação no projeto de arquitetura
}

\author{
- Neliza Maria e Silva Romcy \\ Universidade Federal do Rio Grande do Norte, \\ Brasil \\ neliza.romcy@gmail.com \\ - Marcelo Bezerra de Melo Tinoco \\ Universidade Federal do Rio Grande do Norte, \\ Brasil \\ mmarcelotinoco@gmail.com
}

Investigations into interfaces between parametric modeling and other representation tools in architectural design

\begin{abstract}
Researches about different processes of representation in architectural design allows the acknowledgment about their specificities regarding to potential and limitations. This study aims to investigate the possible interfaces between parametric modeling and other representation media, in order to understand its introduction into design process and its integration with other tools. The methodology consist of literature review to select different media, including sketching, architectural model, BIM and computer-aided manufacturing. As a result, the study identified which processes would be able to assist parametric modeling and suggested possible interfaces between the presented tools.
\end{abstract}

Keywords: Modelagem Paramétrica, Meios de Representação, Processo de Projeto

\section{Introdução}

O caráter essencial da arquitetura está no fato de agir como um vocabulário tridimensional que inclui o homem, trazendo o problema da representação do espaço. Zevi (1996) coloca que, isoladamente ou no seu conjunto, os instrumentos dos quais os projetistas dispõem, como plantas, seções, maquetes, fotografias e cinematografia, são incapazes de representar completamente o espaço arquitetônico em sua totalidade. Porém, o autor ressalta a importância de aprofundar o assunto, como missão de estudar as técnicas disponíveis e tornálas mais úteis. Assim, cada um dos meios para representar o espaço pode ser investigado, aprofundado e melhorado, trazendo uma contribuição original e preenchendo eventuais lacunas uns dos outros.

Inicialmente, a implementação dos sistemas informáticos gerou certa desconfiança no meio arquitetônico, pois era difícil para um arquiteto entender em que sentido um computador poderia ser útil para o seu trabalho. Mesmo utilizando processos de projeto auxiliado por computador (computeraided design - CAD), seu aproveitamento era extremamente limitado: ao herdar uma ideia de desenho de prancheta e replicar esse processo mediante o computador, o potencial do sistema não era completamente aproveitado (Orciuoli, 2010). Nesse caso, a tecnologia CAD era usava principalmente com o propósito de representação final, o que incluía a elaboração de desenhos e simulações realísticas. Em outras palavras, o projeto auxiliado por computador acabava se tornando apenas desenho auxiliado por computador (computer-aided drafting) (Celani, 2002).

$\mathrm{Na}$ última década, o projeto digital (digital design) veio evoluindo como um campo de conhecimento específico que trouxe impactos crescentes nas práticas de projeto e produção, sugerindo um re-exame das teorias e metodologias para guiar pesquisas e desenvolvimentos futuros (Oxman, 2006).

Com os processos de fabricação auxiliada por computador (computer-aided manufacturing - CAM) e a integração das atividades de concepção, análise, fabricação e montagem, surge a possibilidade de se estreitar as lacunas existentes entre projeto e execução, em uma conexão hipoteticamente sem costura entre o conceber (design) e o fazer (making). Porém, como toda ferramenta, cada técnica que abre precedentes para investigações, tem seu próprio conjunto de restrições e modos particulares de se trabalhar (Kolarevic, 2001; Iwamoto, 2009).

Nesse contexto destaca-se a modelagem paramétrica, que permite representar os objetos, não com geometria e propriedades fixas, mas parâmetros e regras que determinam características geométricas e não geométricas. Os parâmetros e regras podem ser expressões que também se relacionam com outros objetos, permitindo atualização automática, de acordo com o controle do usuário ou mudanças de contexto (Eastman et. al, 2011).

A maior alteração do CAD tradicional para a modelagem paramétrica é a possibilidade de interação entre o usuário 
e o modelo. Apresenta-se a mudança de uma modelagem baseada na definição de objetos para uma modelagem baseada na definição de características, restrições e variáveis de um objeto, com foco nas relações entre as partes (Florio, 2012).

$\mathrm{O}$ presente artigo tem como objetivo investigar quais interfaces podem ser estabelecidas entre a modelagem paramétrica eoutros processos de representação, considerando as especificidades de cada um. A partir da investigação sobre essas relações, buscou-se ampliar a compreensão sobre a introdução da modelagem paramétrica no processo de projeto, e identificar possibilidades de integração junto aos outros meios, com contribuições e preenchimento de lacunas.

\section{Metodologia}

O método utilizado consistiu em pesquisa bibliográfica, no intuito de levantar as especificidades dos processos de representação mais comuns em projeto arquitetônico, e identificar suas potencialidades e limitações. A partir do cruzamento com as especificidades da modelagem paramétrica, foi possível investigar e propor o estabelecimento de interfaces e contribuições recíprocas.

Segundo Kowaltowski et al (2006), a combinação de diferentes ferramentas é recomendada, pois permite uma colocação maior de exigências sobre o projeto e o aprofundamento de análise durante o desenvolvimento do produto. Segundo os autores, a concepção que viaja várias vezes do papel para os modelos digitais e físicos deve ser estimulada, trazendo aspectos positivos sobre o processo e o produto final.

Assim, para a seleção dos meios de representação, buscouse incluir processos analógicos e digitais, considerando a bibliografia sobre o tema. Além da modelagem paramétrica, foram investigados: desenhoà mão livre, maquete, modelagem de informação da construção (Bulding Information Modeling - BIM), prototipagem rápida e fabricação digital.

Não foram incluídas as ferramentas computacionais associadas à primeira geração de softwares aplicáveis à arquitetura, geralmente caracterizadas como "pranchetas eletrônicas" ou CAD tradicional.

\section{Resultados}

Longe de serem produtos fortuitos, as representações são resultado do processo de pensar, portanto a capacidade de desenvolvê-las e gerenciá-las é uma das principais habilidades ao projetar. Permite, portanto, a realização de mudanças e experimentações antes da produção do objeto propriamente dito (Lawson, 2011).

$\mathrm{Na}$ busca de estabelecer bases teóricas do projeto arquitetônico auxiliado por computador, Mitchell (2008) define projetar como um processo de operações lógicas para satisfazer predicados de forma e função, declarados em uma linguagem crítica. $O$ autor define o conceito de mundo projetual como aquele desenvolvido pelo projetista para esboçar e investigar possibilidades, se utilizando de meios de representação diversos, como blocos de madeira, linhas desenhadas sobre papel, e sistemas computacionais. Toda vez que uma operação projetual ocorre (movimentação de um bloco de madeira ou inserção de uma nova linha, por exemplo), o mundo projetual sofre uma alteração de estado e traz novas possibilidades na busca de soluções.

Portanto, além da habilidade de utilizar vários instrumentos de representação, é importante que o projetista seja capaz de identificar suas especificidades e selecionar aquele mais adequado para a compreensão dos problemas e soluções envolvidos em cada situação ao longo do processo de projeto.

\section{Análise dos meios de representação selecionados}

O processo paramétrico de projeto é definido como o desenvolvimento de um modelo ou descrição de um problema, onde a representação é baseada nas relações entre objetos controlados por variáveis - os parâmetros (Hudson, 2010).

O entendimento da inter-relação entre as partes e a definição de critérios para a auto-organização do sistema permitem o surgimento de respostas emergentes, que podem tanto retroalimentar a proposição inicial do problema, quanto gerar soluções diversas, porém ainda adequadas. Assim, configura-se a possibilidade de uma arquitetura com potencial generativo (Soares e Tramontano, 2012).

Apesar dos modelos paramétricos serem dinâmicos e de rápida alteração para a investigação de soluções, consistem em estruturas complexas que levam tempo de criação. Como se fundamentam na relação entre objetos, o processo paramétrico de projeto depende da definição dessas relações e da habilidade do projetista durante essa etapa (Woodbury, 2010).

Soma-se, ainda, o desafio de se utilizar o modelo paramétrico em etapas posteriores do projeto, como detalhamento e documentação, quando são necessários desenhos técnicos e a extração de informações exigidas pelos contratantes. Segundo Hudson (2010), o compartilhamento do modelo paramétrico ao longo dessas diversas etapas permitiria o aumento de eficiência, reduziria as cargas de trabalho manual e manteria a continuidade do fluxo de informações.

Em resumo, a modelagem paramétrica traz como potenciais: a possibilidade de relacionar critérios de decisão de projeto em um modelo de informações interconectadas; a dinâmica de alteração de parâmetros para auxílio na tomada de decisão, com a geração, simulação e análise de alternativas; e a contribuição para a estratégia da customização em massa, através da produção de diversas variações de um mesmo modelo/produto.

Como desafio, destaca-se a complexidade do modelo paramétrico, tanto nos momentos de (re) estruturação, quanto para etapas finais do desenvolvimento do projeto, como detalhamento e documentação.

A Figura 1 ilustra as etapas de estruturação de um modelo paramétrico para o estudo de um objeto a partir de suas seções, com sucessivas operações de translação, rotação e escala. É possível perceber como os principais 
elementos são explicitados e relacionados até a configuração do objeto propriamente dito. Uma visão geral do ambiente de programação visual referente ao modelo também foi acrescentada para ilustrar o nível de complexidade.
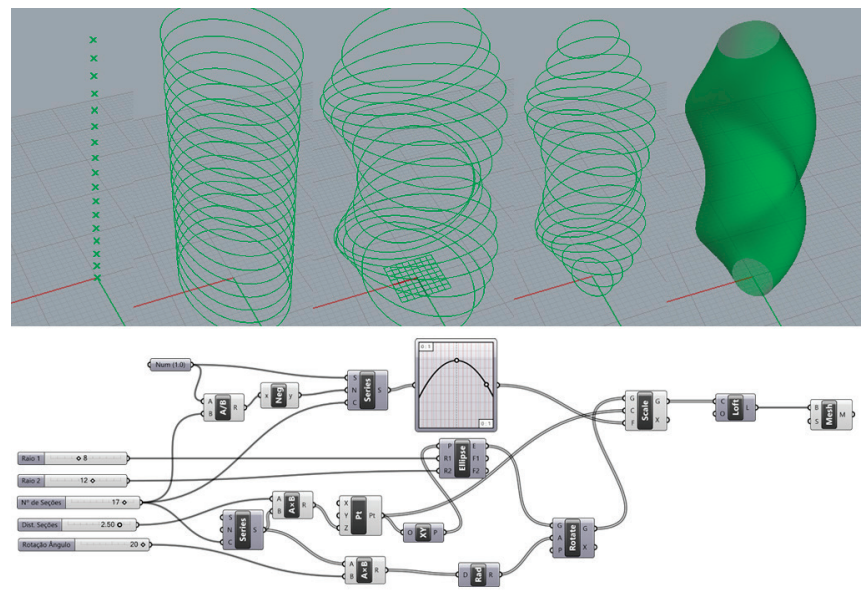

Figura 1: Exemplo de estruturação do modelo paramétrico, considerando a descrição do objeto passo-a-passo e o ambiente de programação visual.

Considerando tais especificidades, os meios de representação previamente selecionados serão analisados a seguir para que sejam investigadas as possíveis interfaces com a modelagem paramétrica.

O desenho à mão livre é o meio mais intuitivo para registrar graficamente observações, ideias e experiências, devido à sua natureza tátil e cinestésica (Ching, 2011). Durante o processo de concepção, como as ideias não fluem de modo contínuo na mente do projetista, o desenho se torna instrumento de busca, investigação e experimentação.

O croqui de concepção se caracteriza como uma espacialização de hipóteses, sem maior definição ou nitidez, que adquire precisão a partir de sucessivas experiências. Trata-se, portanto, de um trabalho de maior uso do autor, nem sempre compreensível para os outros. Com a ideia definida, o projetista passa a registrá-la com maior rigor em desenhos técnicos, como plantas, cortes e fachadas, tornando-se um trabalho de comunicação, passível de ser compreendido por outras pessoas (Schenk, 2010; Yanez e Domínguez, 2004).

Em resumo, os desenhos arquitetônicos podem ser classificados nos seguintes tipos (Kowaltowski et al, 2006):

- Desenhos referenciais - registros de ideias de projetos percebidas pelo projetista, também realizado através do desenho de observação;

- Diagramas - abstrações de ideias, sem representar necessariamente o mundo real ou o projeto com precisão.

- Desenhos de projeto - registros de soluções parciais e colocação de hipóteses, que permitem a análise de suposições em determinado estágio de projeto.

- Desenhos de representação - produzidos após o desenvolvimento do projeto, quando terminado a contento. Inclui os desenhos de representação final, para o cliente ou venda do produto, e os desenhos de execução, para dar suporte à construção da obra.

- Desenhos visionários - representam as qualidades que o projeto deve possuir, podendo exagerar alguns aspectos como escala e luminosidade para enfatizar características ou elementos específicos.

A maquete arquitetônica busca representar um nível do projeto, a partir da visualização plástico-espacial da ideia, e pode desempenhar tanto uma função utilitária quanto uma atividade de criação. Sua utilização permite diversos estudos tridimensionais importantes, como análise de topografia, modelos de massa, aspectos formais, questões de desempenho e execução de detalhes.

Destaca-se, ainda, seu uso na comunicação de ideias, tanto em uma discussão individual do projetista durante o processo de criação, quanto no contato com usuários e clientes com pouca experiência na leitura de desenhos.

Em resumo, as maquetes arquitetônicas podem ser classificadas nos seguintes tipos (Wolfgang e Martin, 2003):

- Maquetes de idealização - se utilizam de meios simples e materiais maleáveis, com processos espontâneos de estruturação e fácil alterabilidade. É considerada por Rocha (2007) como "maquete de solidão" ou "maquete como croqui";

- Maquetes de trabalho - pesquisam de modo mais detalhado e diferenciado as relações plástico-espaciais do projeto, sem antecipar colocações definitivas de configuração;

- Maquetes de execução - mostram o projeto definitivo e em geral tem fins de apresentação, com execução mais precisa da topografia, contexto urbano e questões de escala.

Segundo Pina, Filho e Marangoni (2011), tanto a maquete quanto o croqui introduzem uma abordagem que valoriza o entendimento da questão arquitetônica, e não apenas a solução do problema, levando a respostas mais criativas e pertinentes, passíveis de serem construídas e vivenciadas.

Porém, apesar de o croqui estar disponível desde o início do processo e corresponder à primeira ideia espontânea do projetista, seu nível gráfico é mais abstrato, enquanto a maquete traz a concepção espacial por meio dos elementos tectônicos em uma primeira realização concreta. Nesse caso, a terceira dimensão é real e o objeto pode ser contemplado de ângulos diversos (Wolfgang e Martin, 2003; Kowaltowski et al, 2006).

Dentre os tipos de desenho e maquete apresentados, podem ser destacados para uso conjunto com a modelagem paramétrica: o croqui de concepção, principalmente com o uso de diagrama, e a maquete de idealização.

O diagrama se destaca pela sua capacidade de simplificar uma noção complexa em elementos e relações cruciais, em um processo de eliminação e redução. Sua natureza abstrata permite entender o que há de essencial nos elementos de projeto e suas possíveis relações para gerar diferentes alternativas (Ching, 2011). Do mesmo modo, a maquete de idealização é feita como um ensaio do que se está imaginando, 
extensão do raciocínio e momento de experimentação, porém com contribuições relacionadas à materialidade e tridimensionalidade do objeto.

Assim, por se tratarem de processos espontâneos e de rápida confecção, que enfatizam os principais elementos e relações contidos no objeto projetado, o diagrama e a maquete de idealização contribuem para a (re) estruturação do modelo paramétrico, através de uma maior compreensão do problema/solução, e sua posterior descrição em propriedades fixas e variáveis.

Por outro lado, o trabalho de estruturação do modelo paramétrico explicita a descrição lógica do objeto, antes implícita, e permite alterações rápidas e dinâmicas para a investigação de variações e apoio à tomada de decisão. Tornase possível uma maior precisão e interatividade em processos de geração, análise e simulação de alternativas.

No que diz respeito às tecnologias digitais recentes, foram selecionados o BIM e os processos de produção por prototipagem e fabricação digitais.

O BIM é definido como a criação e uso de informação computacional coordenada e consistente sobre o projeto de uma edificação - informação paramétrica usada para tomada de decisões em projeto, produção de documentação, previsão de desempenho, estimativa de custo e planejamento de obra (Krygiel e Nies, 2008).

A modelagem paramétrica é considerada uma das fundações tecnológicas do BIM (Eastman et. al, 2011), o que permitiu sua diferenciação em relação aos softwares de CAD tradicional. Dessa forma, os elementos de representação não são apenas linhas, planos e volumes, mas objetos associados entre si e a informações adicionais que os caracterizam, como dimensões, materiais e fornecedores.

Ao trabalhar com uma representação virtual da edificação tal qual a prevista para ser construída, é possível gerar simulações tanto no que diz respeito ao seu desempenho, como à sua execução (logística de canteiro), além de permitir a extração de dados mais precisos para quadros quantitativos e fabricação de peças. O modelo deixa de ser apenas 3D e passa a integrar duas novas dimensões: o tempo (4D) e o custo (5D).

Porém, apesar dos modelos BIM serem orientados a objetos, o ferramental existente ainda é mais voltado para a fase de desenvolvimento de projeto do que para a concepção, pois a representação é baseada em categorias/tipos específicos (Ruschel, 2014). Enquanto na modelagem paramétrica é possível estruturar o modelo desde o início e trabalhar em diferentes níveis de abstração, um modelo arquitetônico em BIM, por exemplo, trabalha com objetos já classificados em componentes construtivos, como lajes, paredes, colunas, janelas, portas, escadas, dentre outros.

Assim, a modelagem paramétrica poderia contribuir para a criação e/ou customização de bibliotecas e objetos a serem utilizadosemambienteBIM,enquantoosmodelos BIMsãomais apropriados para as etapas posteriores de desenvolvimento de projeto, como detalhamento, compatibilização, documentação e gerenciamento da obra. Porém, para o estabelecimento dessa troca entre os diferentes modelos, é necessário superar o desafio da interoperabilidade.

A interoperabilidade envolve a capacidade de identificação e troca de dados e informações necessários para serem passados entre diferentes aplicativos, permitindo aos profissionais de diversas disciplinas trocarem ou agregarem informação de maneira colaborativa e ágil (Ruschel et al., 2010). Segundo Kiviniemi et al. (2008), para que um compartilhamento de informações seja possível, deve-se atentar para três fatores:

- Um formato de troca, definindo como compartilhar a informação;

- Uma biblioteca de referência, para definir que informação será compartilhada;

- Os requisitos de informação, definindo quando cada informação será compartilhada.

Com o reconhecimento do potencial de colaboração entre modelagem paramétrica e BIM, alguns exemplos vêm sendo desenvolvidos para estabelecer formatos de troca ou ambientes que integrem essas diferentes funções.

O primeiro consiste no plug-in Dynamo, que insere um ambiente próprio de linguagem de programação visual no aplicativo Revit (AutoDesk), e permite ao projetista um maior controle e personalização de famílias e parâmetros em ambiente BIM.

O segundo consiste em um add-on, lançado em 2015, para a conversão de modelos geométricos gerados no Rhinoceros (Robert McNell \& Associates) para o formato próprio dos objetos e bibliotecas utilizados no aplicativo Archicad (Graphisoft). Considerando que o Rhinoceros trabalha com o plug-in Grasshopper como ambiente próprio de programação visual, a parceria com o Archicad traz a opção de importar modelos desenvolvidos parametricamente diretamente para o ambiente BIM.

Apesar de ainda bastante recentes, tais iniciativas já buscam uma maior continuidade no fluxo de informações entre a modelagem paramétrica propriamente dita e a modelagem de informação da construção, no intuito de aproximar etapas de concepção, desenvolvimento e documentação do projeto.

Por fim, os processos de prototipagem e fabricação digitais se referem a métodos que permitem a transição do modelo digital para o físico de maneira automatizada, onde o produto final pode ser uma maquete, um protótipo ou elementos construtivos.

A prototipagem digital inclui técnicas de prototipagem rápida (sobreposição de camadas), corte a laser, fresas e corte com vinil, para produção de maquetes em escalas reduzidas e protótipos 1:1. A fabricação digital inclui técnicas destinadas à produção de fôrmas ou peças finais de edifícios, com equipamentos de controle numérico (CNC) (Pupo e Celani, 2011).

Segundo Iwamoto (2009), os tipos de técnicas para fabricação digital que tem surgido nos últimos anos são:

- Seccionar (sectioning) - no lugar de construir a superfície em si, a técnica utiliza uma série de perfis, traçados a partir dos contornos dos quais partem as linhas da 
geometria. Trabalha, portanto, com o corte de seções paralelas, dispostas em um determinado intervalo para formar o objeto.

- Tesselação (tessellating) - se utiliza de um conjunto de partes que se encaixam para formar um plano ou superfície, como nos exemplos de mosaicos e vitrais. Através da fabricação digital, possibilita a associação de variação e modulação, com possível economia de material.

- $\quad$ Dobradura (folding) - transforma uma superfície plana em tridimensional, proporcionando ganho de rigidez, vencimento de vãos e auto-sustentação. Tem potencial para economia de material, apelo estético e eficiência em diferentes escalas de projeto.

- Contornar (contouring) - remodela a superfície e cria realces tridimensionais a partir de sucessivas retiradas de material. É um processo subtrativo, semelhante ao ato de esculpir. Considerando que há uma série de materiais de construção dispostos em chapa, pode ser utilizado em produtos como espuma, madeira e metais leves.

- Enformar (forming) - é considerada uma técnica comum na indústria da construção e produção em massa, com a aplicação de moldes ou fôrmas para a geração de uma variedade de peças. Com a fabricação digital, tornouse rentável a fabricação de moldes não padronizados, possibilitando a produção mais eficaz de fôrmas únicas para determinadas aplicações.

As técnicas de fabricação auxiliada por computador resgatam a discussão sobre a necessidade de incorporar os modelos físicos como parte dos processos de concepção, verificação de soluções construtivas e realização de ajustes. Trazem, ainda, novas possibilidades na investigação de formas e materiais, além da integração da cadeia produtiva com componentes aplicados na execução final da própria obra.

Por outro lado, decisões como qual equipamento e método utilizar devem unir intenção de projeto e capacidade das máquinas, trazendo a necessidade de que o projetista compreenda como essas ferramentas trabalham; para quais materiais são mais adequadas; e que possibilidades podem trazer dentro do processo (Iwamoto, 2009).

Sua integração junto à modelagem paramétrica permite um processo contínuo entre a produção dos modelos físicos e o retorno na definição dos parâmetros para ajustes projetuais (Nojimoto, Tramontano e Anelli), o que enriquece a investigação de possibilidades e as tomadas de decisão.

Como os processos paramétricos tem potencial para a customização em série, o estabelecimento de uma cadeia de produção integrada a partir da fabricação digital possibilita, ainda, a geração de elementos diversos - todos provenientes de um mesmo projeto, mas ajustáveis a especificidades da situação (Karzel e Matcha, 2009).

Assim, os modelos paramétricos colaboram com agilidade de ajustes e geração de opções, enquanto os processos de fabricação auxiliados por computador otimizam a produção de modelos físicos, tanto dentro do processo de projeto, quanto para a execução final da obra.

A Figura 2 resume as interfaces sugeridas entre a modelagem paramétrica e os processos de representação identificados: croqui (diagrama), maquete de idealização, BIM e fabricação auxiliada por computador. Buscou-se destacar as possibilidades de contribuição recíproca entre as diferentes ferramentas, tendo a modelagem paramétrica como referência.

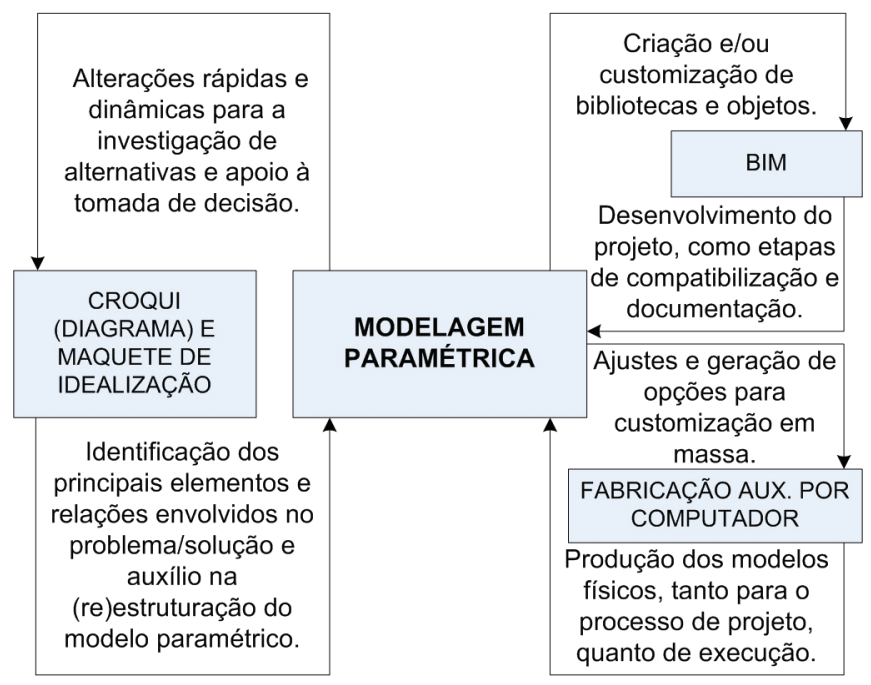

Figura 2: Resumo das interfaces sugeridas entre a modelagem paramétrica e os diferentes processos de representação destacados ao longo do texto.

\section{Discussão}

A investigação sobre os diferentes processos de representação em projeto arquitetônico permite o reconhecimento de suas especificidades no que diz respeito a potenciais e limitações. O presente trabalho buscou contribuir para a discussão das possíveis interfaces entre a modelagem paramétrica e outros meios de representação, ampliando a compreensão sobre sua introdução no processo de projeto e integração junto aos outros meios.

A modelagem paramétrica se caracteriza por gerar objetos dinâmicos, de informação integrada, e rápida alteração para a investigação de soluções. Porém, são estruturas complexas que levam tempo de criação, e podem se tornar de difícil compreensão ou muito robustas à medida que agregam mais elementos em etapas como detalhamento e documentação.

Para a etapa de(re)estruturação dos modelos paramétricos, destaca-se o auxílio de croquis (diagramas) e maquetes de idealização como meios espontâneos e intuitivos, que buscam ressaltar os principais elementos e relações da proposta.

As interfaces com sistemas BIM permitem um fluxo mais contínuo de informações, a partir da transformação de modelos paramétricos topológicos em objetos de categorias específicas da disciplina de projeto, o que aproxima etapas de concepção, desenvolvimento e documentação. 
Por fim, a integração com os processos de prototipagem e fabricação digitais enriquecem tanto o processo de projeto, a partir da tradução de modelos paramétricos em físicos na investigação de possibilidades e tomada de decisão, quanto a cadeia de produção de elementos diversos caracterizados pela customização em massa.

A abordagem paramétrica ressalta a experimentação e a colaboração durante a atividade projetual, ao trabalhar com um modelo de informações interconectadas. Assim, a compreensão de suas interfaces com outros processos de representação enriquece o processo de projeto, pois permite que as diferentes ferramentas colaborem com suas potencialidades e se completem ao longo das diferentes etapas de concepção, desenvolvimento, documentação e materialização.

\section{Agradecimentos}

Agradecimentos à CAPES (Coordenação de Aperfeiçoamento de Pessoal de Nível Superior) pelo apoio financeiro no desenvolvimento da presente pesquisa.

\section{Referências}

Celani, M. G. C. (2002). Beyond analysis and representation in CAD: a new computational approach to design education. Thesis (Doctor of Philosophy (PhD)). Massachusetts Institute of Technology.

Ching, F. D. K. (2011). Representação Gráfica em Arquitetura.

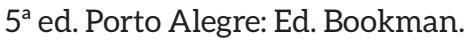

Eastman, C., Teicholz, P., Sacks, R., Liston, K. (2011). BIM Handbook: a Guide to Building Information Modeling for Owners, Managers, Designers, Engineers, and Contractors. Hoboken (NJ): John Wiley \& Sons.

Florio, W. (2012). Notas sobre pensamento e cognição em projetos paramétricos. In: II Encontro da Associação Nacional de Pesquisa e Pós-Graduação em Arquitetura e Urbanismo. Anais...Natal: ENANPARQ.

Hudson, R. (2010). Strategies for Parametric Design in Architecture: An application of practice led research. Thesis (Doctor of Philosophy (PhD)). University of Bath.

Iwamoto, L. (2009) Digital Fabrications: Architectual and Material Techniques. New York: Princeton Architectual Press.

Karzel, R., Matcha, H. (2009). Experimental Design-Build: Teaching Parameter-based Design. In: The New Realm of Architectural Design: 27th eCAADe Conference Proceedings. Istanbul: ECAADE. 153-158.

Kiviniemi, A., Tarandi, V., Karlshøj, J., Bell, H., Karud, O. J. (2008). Review of the Development and Implementation of IFC compatible BIM. European Research Area: ERABUILD.

Kolarevic, B. (2001) Designing and Manufacturing Architecture in the Digital Age. In: Architectural Information Management: 19th eCAADe Conference Proceeding. Helsinki:
ECAADE. 117-123.

Kowaltowski, D. C. C. K.; Celani, M. G. C.; Moreira, D. C.; Pina, S. A. M.; Ruschel, R. C.; Silva, V. G.; Labaki, L. C.; Petreche, J. R. (2006). Reflexão sobre metodologias de projeto arquitetônico. Ambiente Construído, v. 6, n. 2, 7-19.

Krygiel, E.; Nies, B. (2008). Green BIM: successful sustainable design with building information modeling. Indianapolis: Wiley Publishing, Inc.

Lawson, B. (2011). Como arquitetos e designers pensam. São Paulo: Oficina de Textos.

Mitchell, W. J. (2008). A lógica da arquitetura: projeto, computação e cognição. Campinas, SP: Editora da Unicamp.

Nojimoto, C., Tramontano, M, Anelli, R. L. S. (2011). Design Paramétrico: Experiência Didática. In: SIGraDi - XV Congreso de La Sociedad Iberoamericana de Grafica Digital. Anais... Santa Fé: SIGraDI. 1-5.

Orciuoli, A. (2010). Projeto assistido por computador: ontem, hoje, amanhã. Revista Arquitetura e Urbanismo, 197, 108-111. Oxman, R. (2006) Theory and design in the first digital age. Design Studies, 27 (3), 229-265.

Pina, S. A. M., Filho, F. B, Marangoni, R. F. (2011). Maquetes e modelos comoestímuloà criatividade no projeto arquitetônico. In: D. C. C. K. Kowaltowski, D. C. Moreira, J. R. D. Petreche, M. M. Fabricio. (orgs.) O processo de projeto em arquitetura: da teoria à tecnologia. São Paulo: Oficina de textos.

Pupo, R., Celani, M. G. C. (2011). Prototipagem rápida e fabricação digital na arquitetura: fundamentação e formação. In: D. C. C. K. Kowaltowski, D. C. Moreira, J. R. D. Petreche, M. M. Fabricio. (orgs.) O processo de projeto em arquitetura: da teoria à tecnologia. São Paulo: Oficina de textos.

Rocha, P. M. (2007). Maquete de papel. São Paulo: Cosac Naify. Ruschel, R. C. (2014). To BIM or not to BIM? In: III Encontro da Associação Nacional de Pesquisa e Pós-Graduação em Arquitetura e Urbanismo. Anais...São Paulo: ENANPARQ.

Ruschel, R. C., Andery, P. R. P., Motta, S. R. F., Veiga, A. C. N. R. (2010) Building Information Modeling para projetistas. In: Fabrício, M. M., Ornstein, S. W. (orgs.) Qualidade no projeto de edifícios. São Carlos: RiMa Editoria.

Schenk, L. R. (2010). Os Croquis na Concepção Arquitetônica. São Paulo: Annablume.

Tramontano, M., Soares, J.P. (2012). Arquitetura emergente, design paramétricos e o representar através de modelos de informação. V!RUS, 8. Disponível em: http://www.nomads. usp.br/virus/virus08/?sec=7\&item=1\&lang=pt

Wolfgang, K., Martin, H. (2003). Maquetes arquitetônicas. São Paulo: Martins Fontes.

Woodbury, R. (2010). Elements of parametric design. New York: Routledge.

Yanes, M. D., Domínguez, E. R. (2004). Desenho livre para arquitectos. Lisboa: Editorial Estampa Lda.

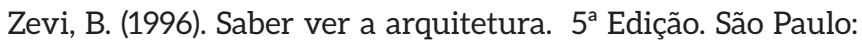
Martins Fontes. 